\title{
Evaluation of the safety and efficacy of pregabalin in older patients with neuropathic pain: results from a pooled analysis of 11 clinical studies
}

\author{
David Semel', T Kevin Murphy, Gergana Zlateva, Raymond Cheung, Birol Emir
}

\begin{abstract}
Background: Older patients are typically underrepresented in clinical trials of medications for chronic pain. A post hoc analysis of multiple clinical studies of pregabalin in patients with painful diabetic peripheral neuropathy (DPN) or postherpetic neuralgia (PHN) was conducted to evaluate the efficacy and safety of pregabalin in older patients.

Methods: Data from 11 double-blind, randomized, placebo-controlled clinical studies of pregabalin in patients with DPN or PHN were pooled. Efficacy outcomes included change in Daily Pain Rating Scale score, $\geq 30 \%$ and $\geq 50 \%$ responders, and endpoint pain score $\leq 3$. Safety was based on adverse events (AEs). Primary efficacy was analyzed by analysis of covariance with terms for treatment, age category, protocol, baseline pain, and treatment-by-age category interaction.

Results: 2516 patients (white, $\mathrm{n}=2344$ [93.2\%]; men, $\mathrm{n}=1347$ [53.5\%]; PHN, $\mathrm{n}=1003$ [39.9\%]; pregabalin, $\mathrm{n}=$ 1595) were included in the analysis. Patients were grouped by age: 18 to 64 years ( $n=1236), 65$ to 74 years $(n=$ 766), and $\geq 75$ years $(n=514)$. Baseline mean pain and sleep interference scores were comparable across treatment and age groups. Significant improvements in endpoint mean pain were observed for all pregabalin dosages versus placebo in all age groups ( $\mathrm{x}$ 0.0009), except for the lowest dosage (150 mg/day) in the youngest age group. Clinically meaningful pain relief, defined as $\geq 30 \%$ and $\geq 50 \%$ pain response, was observed in all age groups. The most common AEs were dizziness, somnolence, peripheral edema, asthenia, dry mouth, weight gain, and infections. The relative risks for these AEs increased with pregabalin dose, but did not appear related to older age or type of neuropathic pain.

Conclusions: Pregabalin (150-600 mg/day) significantly reduced pain in older patients (age $\geq 65$ years) with neuropathic pain and improvements in pain were comparable to those observed in younger patients. Titration of pregabalin to the lowest effective dose should allow for effective pain relief while minimizing AEs in older patients with neuropathic pain. Given the common use of polypharmacy in older patients, the absence of known drug-drug interactions makes pregabalin an important treatment option for older patients with pain of neuropathic origin.
\end{abstract}

\section{Background}

Chronic neuropathic pain conditions, such as painful diabetic peripheral neuropathy (DPN) and postherpetic neuralgia (PHN), can be challenging to manage in older patients. Older patients tend to have multiple medical conditions and take several medications, which complicate treatment decisions. Concerns include the potential for drug-drug and drug-disease interactions and age-related

\footnotetext{
* Correspondence: david.semel@pfizer.com

Pfizer Global Pharmaceuticals, New York, NY, USA
}

changes in drug absorption, metabolism, and excretion [1-4]. Several studies have shown that high proportions (e.g. 34\%-50\%) of older patients (age $\geq 65$ years) with neuropathic pain conditions had evidence of potentially inappropriate pain medication use based on a contraindication, warning, or potential drug-drug interaction $[5,6]$. Propoxyphene, tertiary tricyclic antidepressants (TCAs) (e.g. amitriptyline), and benzodiazepines were the most commonly used inappropriate medications in one study of elderly patients with neuropathic pain [5]. In patients with cardiovascular comorbidities, TCAs have been associated

c 2010 Semel et al; licensee BioMed Central Ltd. This is an Open Access article distributed under the terms of the Creative Commons 
with a dose-related increased risk of sudden cardiac death and thus should be used with caution [7].

Pregabalin is a calcium channel $\alpha_{2} \delta$ ligand with analgesic, anxiolytic, and anticonvulsant properties that is minimally metabolized with renal excretion, displays linear gastrointestinal absorption leading to a predictable dose-response relationship, and has no known drugdrug interactions [8]. Clinical trials have shown the efficacy and safety of pregabalin at dosages ranging from 150 to $600 \mathrm{mg} /$ day in patients $\geq 18$ years of age with painful DPN or PHN [9-17]. In these studies, patients with DPN or PHN who received pregabalin at dosages of $300 \mathrm{mg} /$ day $[9,10,12,13,15]$ or $600 \mathrm{mg} /$ day $[9-11,14,15,17]$ experienced significant reductions in pain compared with placebo. Pregabalin administered at flexible dosages of 150 to $600 \mathrm{mg} /$ day depending on patient response and tolerability was also shown to reduce endpoint mean pain compared with placebo in patients with DPN or PHN [14]. Across studies, results were mixed for the $150-\mathrm{mg} /$ day dosage, with significant pain reductions observed in 2 studies of patients with PHN $[13,15]$ but not in another study of patients with DPN [11]. Pregabalin $75 \mathrm{mg} /$ day did not significantly reduce pain in DPN [10]. One study of patients with DPN showed significant differences on endpoint mean pain only in the group that received $600 \mathrm{mg} /$ day, but not in the groups who received 150 or $300 \mathrm{mg} /$ day [16].

Clinical studies of therapies for chronic pain typically lack sufficient numbers of older patients to evaluate the safety and efficacy of analgesics in this population. Current evidence suggests that selection of treatment for neuropathic pain in older patients should be similar to that for younger patients, with the exception of slower, more cautious dosing and consideration for issues unique to the older population [1]. The objective of this post hoc analysis was to evaluate the efficacy and safety of pregabalin in older patients with neuropathic pain using pooled doubleblind, randomized, placebo-controlled studies of pregabalin in patients with DPN or PHN.

\section{Methods}

\section{Clinical Study Selection}

The goal of this analysis was to break down efficacy and safety data by specific age cut-offs, which would have been difficult or impossible to obtain using summary statistics from published reports. Furthermore, it has been suggested that study-level analyses can lead to biased assessments, and use of aggregated summary values has some limitations for explaining the heterogeneity of results [18-20]. Access to a rich, in-house, patient-level database provided us with the flexibility to analyze data using specific age cut-offs and allowed for increased precision of our estimates. Thus, this post hoc analysis was based entirely on data from in-house, Pfizer
Inc.-sponsored, clinical studies. Clinical studies of patients with DPN or PHN were pooled if they met the following criteria: 1) were Pfizer Inc.-sponsored studies completed prior to the end of 2006; 2) were randomized, parallel, placebo-controlled, and double-blind; 3 ) had at least 1 fixed-dose pregabalin treatment arm; 4) had in-house, patient-level efficacy and safety data available; 5) had similar treatment durations; and 6) had same primary outcome. Of the 22 Pfizer Inc.-funded clinical studies of patients with DPN and/or PHN that were completed prior to the end of 2006, 8 studies were excluded from this analysis because they failed to meet criterion 2 (e.g. open-label); 2 studies did not meet criterion 3 (e.g.; only flexible-dose pregabalin arms) and 1 study did not meet criterion 6 .

\section{Post hoc Analysis}

Data from 11 double-blind, randomized, placebo-controlled, Pfizer Inc.-sponsored studies that evaluated the efficacy and safety of pregabalin in patients with DPN or PHN were used for this analysis. Results from 9 of these studies have been reported [9-17]. Results of the other 2 studies, 1008-030 and 1008-040, have been summarized in a review article [21] and a European Public Assessment Report Scientific Discussion posted at the European Medicines Agency Web site [22]; additionally, a synopsis of study 1008-040 has been posted at the PhRMA Clinical Study Results Web site [23]. The studies that met the selection criteria had a similar design with a 1-week baseline period followed by 5 to 13 weeks of placebo-controlled, double-blind treatment. Most included a 1-week titration period in the double-blind phase; 1 study had no titration period [16] and another had a 2-week titration period [11]. In these studies, patients were randomized to receive pregabalin at fixed dosages ranging from 75 to $600 \mathrm{mg} /$ day or placebo. One study included a flexible-dose pregabalin 150- to 600mg/day treatment arm [14].

All studies were conducted in compliance with the Declaration of Helsinki and the International Conference on Harmonization Good Clinical Practice Guideline. The final study protocols, any amendments, and informed consent documentation were approved by the Institutional Review Board(s) and/or Independent Ethics Committee(s) at each investigational center. The clinical protocols were conducted in accordance with Food and Drug Administration Regulations.

\section{Patient Population}

Eligible patients were male and female patients aged $\geq 18$ years with DPN or PHN; one study required patients at sites in Austria to be $\geq 19$ years of age. Patients with DPN had a diagnosis of diabetes mellitus type 1 or type 2 and a diagnosis of painful DPN for $\geq 1$ years, except 
for 2 studies that included patients with painful DPN for $\geq 3$ months [17] and $\geq 6$ months [14]. Patients with PHN must have had pain present for $\geq 3$ months $[9,14,15]$ or $>6$ months [13] after healing of herpes zoster rash, depending on the study. Female patients were required to be nonpregnant, not lactating, surgically sterile, postmenopausal, or use an effective form of contraception. Patients were included if they had scores $\geq 40 \mathrm{~mm}$ on the visual analog scale of the Short-Form McGill Pain Questionnaire at screening and randomization, and had an average Daily Pain Rating Scale (DPRS) score $\geq 4$ derived from at least 4 diary entries during the 1 -week baseline period. Patients were excluded if they had low creatinine clearance $\left(\mathrm{CL}_{\mathrm{cr}}\right.$; defined as $\leq 30 \mathrm{~mL} / \mathrm{min}[9,15,16]$ or $\leq 60$ $\mathrm{mL} / \mathrm{min}[10,12,14,17]$ depending on the study). In 2 studies of patients with PHN $[9,15]$, the dose of pregabalin was adjusted based on baseline renal function. Patients with $\mathrm{CL}_{\mathrm{cr}}>60 \mathrm{~mL} / \mathrm{min}$ received pregabalin $600 \mathrm{mg} /$ day and those with $\mathrm{CL}_{\mathrm{cr}}$ values of $>30$ to $60 \mathrm{~mL} / \mathrm{min}$ were assigned to $300 \mathrm{mg} /$ day. Patients with DPN were required to have hemoglobin $\mathrm{A}_{1 \mathrm{c}}$ levels $\leq 11 \%$. Six of the 11 studies excluded patients who had previously failed to respond to gabapentin at dosages $\geq 1200 \mathrm{mg} /$ day for the treatment of DPN or PHN $[9,10,12,13,22,23]$.

\section{Efficacy and Safety Assessments}

The primary efficacy measure was the endpoint average pain score on DPRS $(0=$ no pain to $10=$ worst possible pain). Endpoint mean pain was based on patients' pain score ratings over the last 7 days of treatment. The Initiative on Methods, Measurement, and Pain Assessment in Clinical Trials (IMMPACT) group recommends the use of responder analyses rather than mean changes in pain to determine clinically meaningful change in pain in clinical trials of chronic pain [24]. Patients who experience $\mathrm{a} \geq 30 \%$ reduction in pain are considered to have a moderately important improvement in pain and those who experience a $\geq 50 \%$ reduction in pain, a substantial improvement in pain [24]. Furthermore, a pain score of $\leq 3$ on the DPRS (no worse than mild pain) at endpoint represents an ideal outcome for patients with chronic pain [25]. Other outcome measures included sleep interference score on Daily Sleep Interference Scale (DSIS; $0=$ pain did not interfere with sleep to 10 = pain completely interfered with sleep) and safety. Both pain and sleep interference scores on the DPRS and DSIS, respectively, were recorded daily by patients in diaries upon waking. Safety was assessed from treatment-emergent adverse events (AEs) and study discontinuations owing to AEs reported during the studies.

\section{Statistical Analyses}

For the pooled analysis, patients with DPN or PHN were combined and stratified into the following age groups: 18 to 64 years, 65 to 74 years, and $\geq 75$ years. Only data for pregabalin at dosages of 150 to $600 \mathrm{mg} /$ day were evaluated because $75 \mathrm{mg} /$ day is not an approved dosage. Demographics and baseline characteristics (mean DPRS and DSIS sleep interference scores) were summarized descriptively by treatment and disease groups.

To explore the differential effects on pain among age groups, a treatment-by-age interaction analysis was performed on patients using analysis of covariance with terms for treatment, age category, protocol, baseline pain, and treatment-by-age category interaction. Last observation carried forward (LOCF) was used to impute missing values for the evaluation of response rates for endpoint pain score $\leq 3$ and $30 \%$ and $50 \%$ pain relief. The more conservative baseline observation carried forward (BOCF) method of imputation was also used to evaluate response rates for both $30 \%$ and $50 \%$ pain relief, but not endpoint pain score $\leq 3$ since patients were required to have a pain score $\geq 4$ on the DPRS at baseline for inclusion in these studies. The most common AEs ( $\geq 10 \%$ of any age or treatment group) were tabulated by treatment and age groups. The $95 \%$ confidence intervals $(\mathrm{CI})$ for relative risks for pregabalin 300 $\mathrm{mg} /$ day (most common dosage) versus placebo were displayed by age groups.

\section{Results}

In total, 2516 patients were included in the pooled analysis: 1513 patients with DPN and 1003 patients with PHN. In the overall pooled group, 93.2\% were white, $53.5 \%$ were male, and $50.9 \%$ were $\geq 65$ years of age. Among patients with DPN, 57.6\% were male and 32.6\% were $\geq 65$ years of age; among patients with PHN, $47.5 \%$ were male and $78.4 \%$ were $\geq 65$ years of age (Table 1 ). Baseline mean pain scores and mean sleep interference scores were comparable among age and dosage groups (Figure 1).

Comparable dose-related improvements in endpoint mean pain score were observed for pregabalin across age groups (Figure 2A). Similar results were observed for improvements in endpoint mean sleep interference scores (Figure 2B). Interestingly, the placebo response on pain and sleep interference scores appeared higher in the younger age group compared with the older age groups. While these results suggested a trend for increasing pregabalin-mediated pain reductions with increasing age, driven by an inverse relationship between placebo response and age, it was not statistically significant. Placebo-corrected least squares mean differences in pain with pregabalin between age groups were -0.155 (95\% CI: $-0.412,0.109 ; \mathrm{p}=0.2497$ ) for patients aged 18 to 64 years versus $\geq 75$ years; -0.157 (95\% CI: -0.419 , $0.105 ; \mathrm{p}=0.2402)$ for patients aged 65 to 74 years 
Table 1 Demographic and clinical characteristics at baseline

\begin{tabular}{|c|c|c|c|c|c|c|c|c|}
\hline \multirow[t]{2}{*}{ Characteristic } & \multicolumn{4}{|c|}{ Diabetic peripheral neuropathy } & \multicolumn{4}{|c|}{ Postherpetic neuralgia } \\
\hline & $\begin{array}{l}\text { Placebo } \\
(n=558)\end{array}$ & $\begin{array}{c}\text { Pregabalin } \\
150 \mathrm{mg} / \\
\text { day } \\
(\mathrm{n}=176)\end{array}$ & $\begin{array}{c}\text { Pregabalin } \\
300 \mathrm{mg} / \\
\text { day } \\
(\mathrm{n}=266)\end{array}$ & $\begin{array}{c}\text { Pregabalin } \\
600 \mathrm{mg} / \\
\text { day } \\
(\mathrm{n}=513)\end{array}$ & $\begin{array}{l}\text { Placebo } \\
(n=363)\end{array}$ & $\begin{array}{c}\text { Pregabalin } \\
150 \mathrm{mg} / \\
\text { day } \\
(\mathrm{n}=251)\end{array}$ & $\begin{array}{c}\text { Pregabalin } \\
300 \mathrm{mg} / \\
\text { day } \\
(\mathrm{n}=230)\end{array}$ & $\begin{array}{c}\text { Pregabalin } \\
600 \mathrm{mg} / \\
\text { day } \\
(\mathrm{n}=159)\end{array}$ \\
\hline Male, n (\%) & $308(55.2)$ & $110(62.5)$ & $144(54.1)$ & $309(60.2)$ & $180(49.6)$ & $117(46.6)$ & $103(44.8)$ & $76(47.8)$ \\
\hline \multicolumn{9}{|l|}{ Age, n (\%) } \\
\hline $18-64$ y & $366(65.6)$ & $127(72.2)$ & $182(68.4)$ & $344(67.1)$ & $68(18.7)$ & $57(22.7)$ & 45 (19.6) & $47(29.5)$ \\
\hline $65-74$ y & $158(28.3)$ & $39(22.2)$ & $62(23.3)$ & $139(27.1)$ & $143(39.4)$ & $92(36.6)$ & $64(27.8)$ & $69(43.4)$ \\
\hline$\geq 75$ y & $34(6.1)$ & $10(5.7)$ & $22(8.3)$ & $30(5.8)$ & $152(41.9)$ & $102(40.6)$ & $121(52.6)$ & $43(27.0)$ \\
\hline \multicolumn{9}{|l|}{ Race } \\
\hline White & $496(88.9)$ & $167(94.9)$ & $243(91.4)$ & $460(89.7)$ & $354(97.5)$ & $244(97.6)$ & $226(99.1)$ & $154(96.9)$ \\
\hline Black & $28(5.0)$ & $3(1.7)$ & $10(3.8)$ & $22(4.3)$ & $2(0.5)$ & $4(1.6)$ & $2(0.9)$ & $1(0.6)$ \\
\hline Hispanic & $24(4.3)$ & $2(1.1)$ & $7(2.6)$ & $20(3.9)$ & $4(1.1)$ & $2(0.8)$ & $1(0.4)$ & $4(2.5)$ \\
\hline $\begin{array}{l}\text { Asian or Pacific } \\
\text { Islander }\end{array}$ & $2(0.4)$ & $2(1.1)$ & $3(1.1)$ & $5(1.0)$ & $2(0.5)$ & $1(0.4)$ & 0 & 0 \\
\hline $\begin{array}{l}\text { Alaskan or Native } \\
\text { American }\end{array}$ & $1(0.2)$ & 0 & $1(0.4)$ & 0 & 0 & 0 & 0 & 0 \\
\hline Other & $7(1.3)$ & $2(1.1)$ & $2(0.8)$ & $6(1.2)$ & $1(0.3)$ & 0 & $1(0.4)$ & 0 \\
\hline Weight, kg, mean (SD) & $92.6(20.6)$ & $91.1(17.8)$ & $93.6(20.1)$ & $93.1(19.8)$ & $74.7(15.7)$ & $73.9(15.6)$ & $69.8(13.6)$ & $77.8(13.9)$ \\
\hline Height, $\mathrm{cm}$, mean (SD) & $170.8(10.1)$ & $172.3(10.2)$ & $171.4(10.1)$ & $171.2(9.9)$ & $167.0(9.9)$ & $165.5(9.8)$ & $165.3(10.5)$ & $166.3(11.1)$ \\
\hline \multicolumn{9}{|l|}{$\mathrm{CL}_{c r}, \mathrm{~mL} / \mathrm{min}$} \\
\hline Mean (SD) & $101.9(37.3)$ & $101.0(33.0)$ & $101.7(36.7)$ & $98.5(30.3)$ & $69.9(26.5)$ & $68.7(24.3)$ & $63.2(24.3)$ & $84.8(22.3)$ \\
\hline $\mathrm{N}$ & 554 & 175 & 265 & 511 & 362 & 250 & 230 & 156 \\
\hline \multicolumn{9}{|l|}{ Baseline pain ${ }^{a}$} \\
\hline Mean (SD) & $6.5(1.6)$ & $6.3(1.4)$ & $6.4(1.4)$ & $6.6(1.6)$ & $6.6(1.5)$ & $6.6(1.6)$ & $6.8(1.5)$ & $6.5(1.5)$ \\
\hline N & 550 & 175 & 265 & 508 & 361 & 250 & 230 & 154 \\
\hline \multicolumn{9}{|l|}{ Baseline sleep ${ }^{b}$} \\
\hline Mean (SD) & $5.3(2.4)$ & $5.1(2.4)$ & $5.6(2.2)$ & $5.4(2.6)$ & $4.6(2.7)$ & $4.5(2.5)$ & $4.8(2.6)$ & $4.8(2.4)$ \\
\hline $\mathrm{N}$ & 549 & 175 & 265 & 508 & 361 & 250 & 230 & 154 \\
\hline
\end{tabular}

${ }^{a}$ Daily Pain Rating Scale score

${ }^{b}$ Daily Sleep Interference Scale score

$\mathrm{SD}$ : standard deviation; $\mathrm{CL}_{\mathrm{cr}}$ : creatinine clearance

versus $\geq 75$ years; and 0.002 (95\% CI: $-0.215,0.218 ; \mathrm{p}=$ 0.9882 ) for patients aged 18 to 64 years versus 65 to 74 years.

To better understand the apparent differences in placebo response among age groups, we defined a contrast in our model in the placebo group. Overall, there were significant differences among age groups in placebo patients with respect to pain relief $(\mathrm{p}=0.005)$, indicating a trend for decreasing placebo response with older age. Placebo patients aged 18 to 64 years showed the largest improvement in average pain score $(-1.47)$ compared with either placebo patients aged 65 to 74 years $(-1.05 ; \mathrm{p}=0.0112)$ or aged $\geq 75$ years $(-0.86 ; \mathrm{p}=0.0031)$. No significant differences in placebo pain response were observed between those aged 65 to 74 years and those aged $\geq 75$ years $(\mathrm{p}=0.3318)$.

Significant dose-dependent reductions in endpoint mean pain score on DPRS were observed for pregabalin dosages of 150,300 , and $600 \mathrm{mg} /$ day versus placebo for pooled age groups $(\mathrm{p}<0.0001$; Figure $3 \mathrm{~A})$. For patients aged $\geq 75$ years, significant improvements in endpoint mean pain score were observed for pregabalin versus placebo at all dosages (150 mg/day pregabalin-placebo difference, - 0.90 [p = 0.0005]; $300 \mathrm{mg} /$ day pregabalin-placebo difference, -1.37 [p < 0.0001]; $600 \mathrm{mg} /$ day pregabalin-placebo difference, -1.81 [ $<0.0001]$; Figure 3B). Significant differences in placebo-corrected endpoint mean pain were also observed for all pregabalin dosages in patients aged 65 to 74 years $(150 \mathrm{mg} /$ day pregabalin-placebo difference, -0.77 [p = 0.0009]; $300 \mathrm{mg} /$ day pregabalin-placebo difference, -1.28 [p < 0.0001]; $600 \mathrm{mg} /$ day pregabalin-placebo difference, -1.71 [p $<0.0001$ ]; Figure $3 B$ ). In patients aged 18 to 65 years, pregabalin provided significant improvements in the 300-mg/day (pregabalin-placebo difference, $-0.67[\mathrm{p}=$ $0.0003]$ ) and 600-mg/day (pregabalin-placebo difference, -1.08 [p $<0.0001]$ ) dosage groups, but not the $150-\mathrm{mg} /$ day 
A.

\section{Placebo \\ Pregabalin 150 mg/day \\ Pregabalin 300 mg/day \\ Pregabalin $600 \mathrm{mg} /$ day}

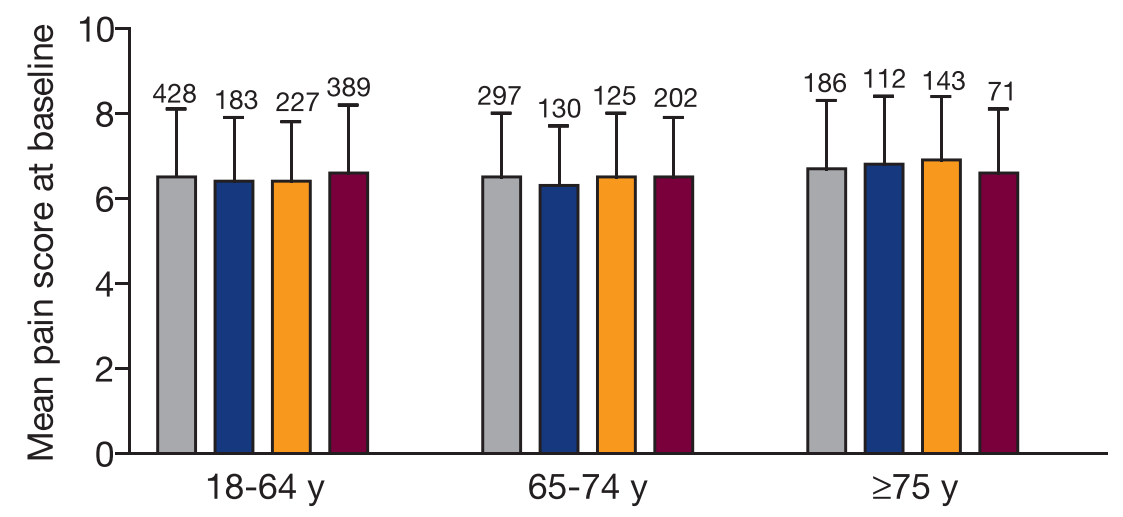

B.
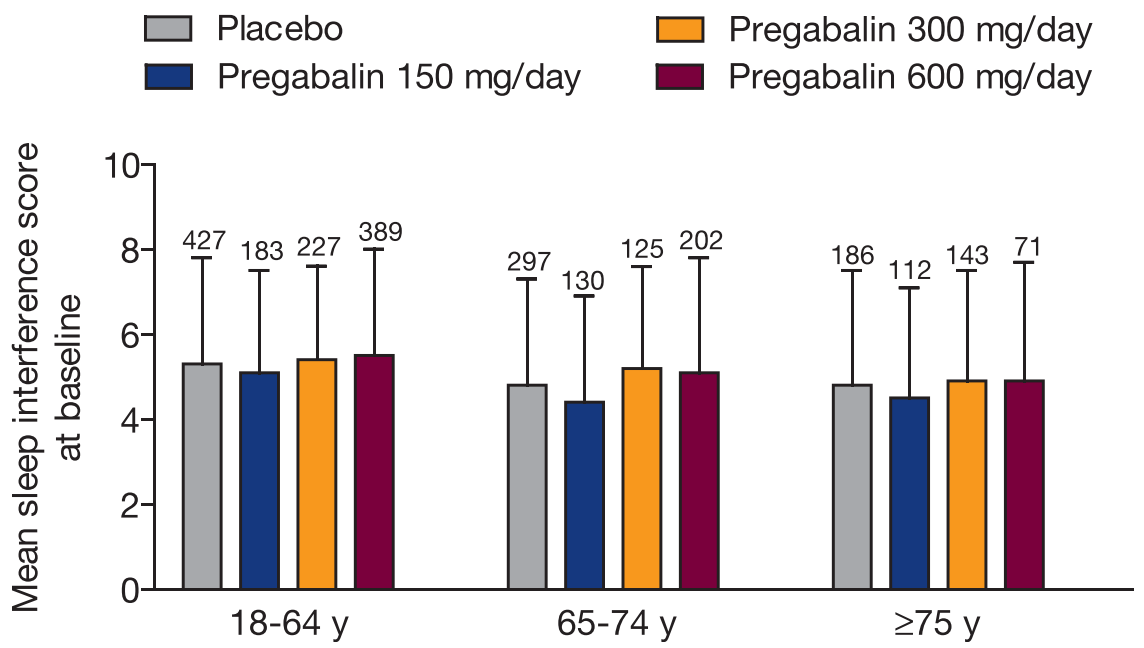

Figure 1 Baseline mean pain (A) and sleep interference (B) scores by age and dosage group. Error bars represent standard deviation of the mean. Number above each bar is number of patients.

group (pregabalin-placebo difference, $-0.30[\mathrm{p}=0.128]$; Figure 3B).

Because of the heterogeneity of response in patients with neuropathic pain, it is important not only to look at mean changes in pain, but also the proportion of patients with clinically defined response criteria. Generally, higher response rates were observed for $\geq 30 \%$ pain relief, $\geq 50 \%$ pain relief, and pain score at endpoint $\leq 3$ with increasing pregabalin dose in all age groups (Table 2). Moderately important improvements in pain $(\geq 30 \%$ reduction) were observed in one-third to more than one-half of patients and substantial improvements in pain ( $\geq 50 \%$ reduction) in one-fifth to nearly one-half of patients who received 150 to $600 \mathrm{mg} /$ day pregabalin across age groups regardless of the method of imputation (Table 2). Furthermore, one-quarter to nearly onehalf of patients had pain scores $\leq 3$ at endpoint reflecting mild pain following treatment with 150 to $600 \mathrm{mg}$ /day pregabalin (Table 2).

The most common AEs that occurred in $\geq 10 \%$ of any age or treatment group were dizziness, somnolence, peripheral edema, asthenia, dry mouth, weight gain, and infection. In patients with either DPN or PHN, the percentage of patients with a given $\mathrm{AE}$ was not noticeably different in patients aged $\geq 75$ years versus those aged 65 to 74 years (Table 3 ). The relative risks for the most 
A.

Placebo

$\square$ Pregabalin $150 \mathrm{mg} /$ day
Pregabalin 300 mg/day

$\square$ Pregabalin 600 mg/day

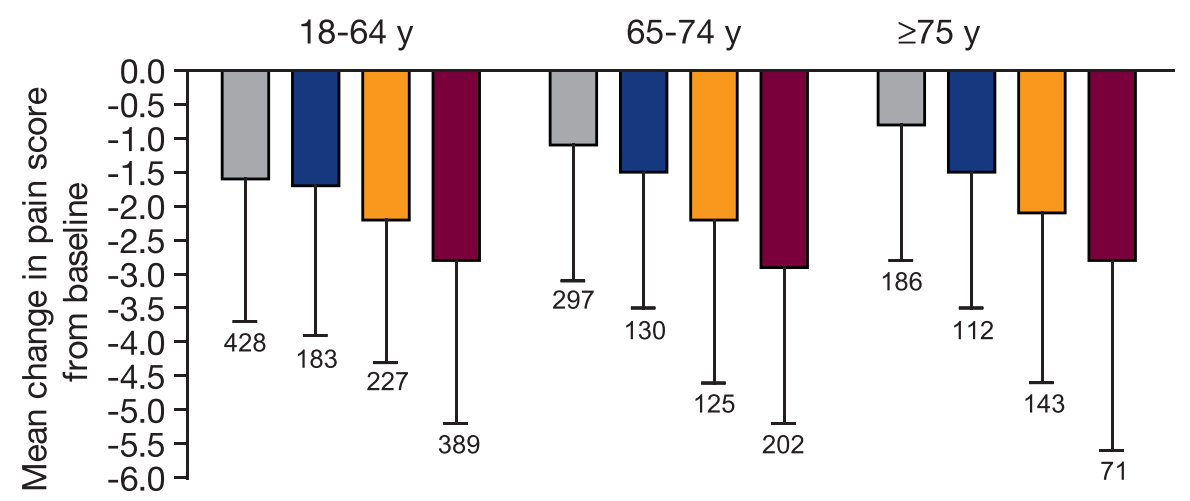

B.
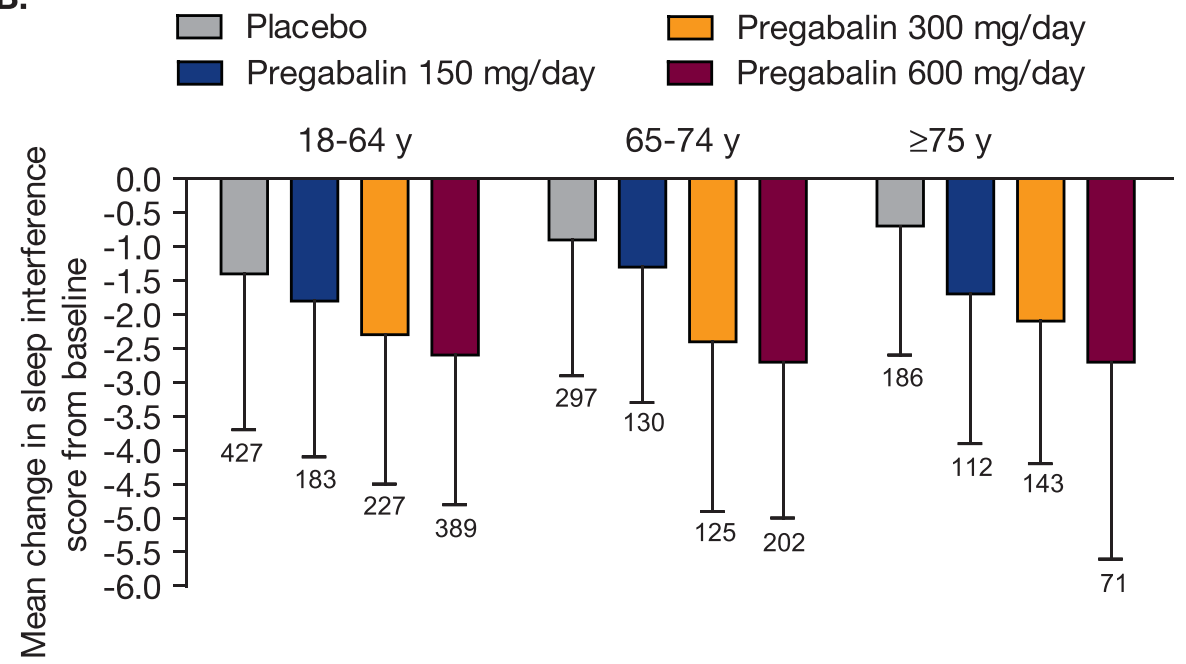

Figure 2 Change in mean pain (A) and sleep interference (B) scores at endpoint. Error bars represent standard deviation of the mean. Number above each bar is number of patients.

common AEs for pregabalin versus placebo are shown for pregabalin $300 \mathrm{mg} /$ day, a dosage commonly used for the treatment of neuropathic pain (Figure 4). While an increased risk $(>1)$ was observed for several AEs relative placebo (e.g. somnolence and dizziness), the point estimates for the relative risks did not uniformly increase with older age and the corresponding 95\% CI overlapped among age groups (Figure 4). The relative risks for the most common AEs increased with pregabalin dose, but appeared unrelated to age regardless of dose (Figure 4 and Additional files 1 and 2). Study discontinuations owing to AEs were generally higher for pregabalin $300 \mathrm{mg} /$ day and $600 \mathrm{mg} /$ day compared with placebo or pregabalin $150 \mathrm{mg} /$ day across all age groups
(Table 4). A trend for higher AE-related discontinuations with increasing age was observed, particularly in patients with PHN at the higher pregabalin doses.

\section{Discussion}

The findings from this post hoc pooled analysis showed that the efficacy and safety of pregabalin in older patients with neuropathic pain are comparable to those observed in younger patients with neuropathic pain. Clinically meaningful and robust efficacy for pregabalin was observed in both older and younger patients, even using the more conservative BOCF method for imputing missing data. Additionally, the response rates in this study for $\geq 30 \%$ pain relief and $\geq 50 \%$ pain relief were 
A.

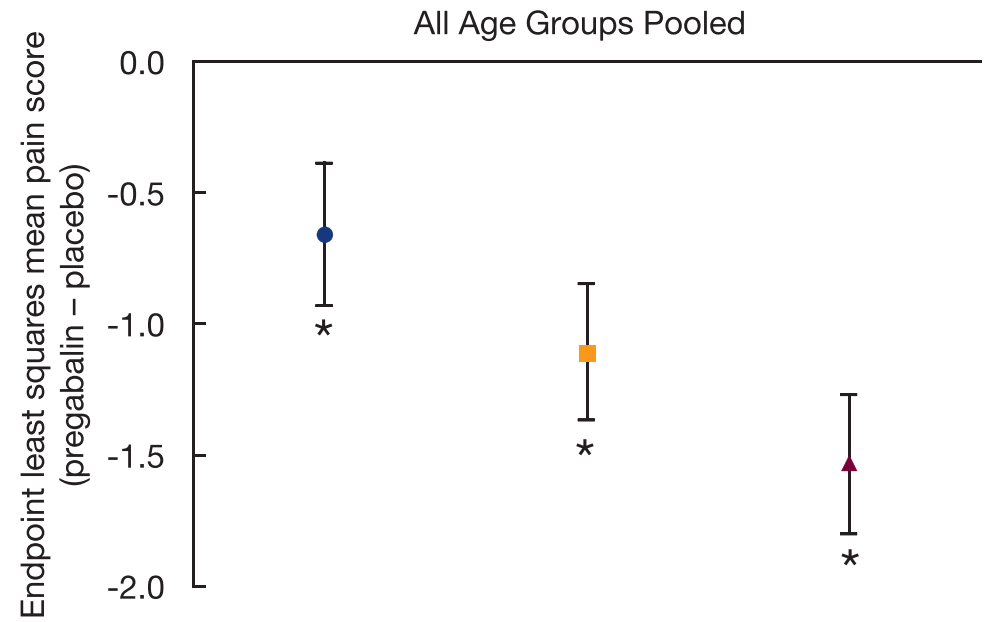

- Pregabalin $150 \mathrm{mg} /$ day

- Pregabalin $300 \mathrm{mg} /$ day

A Pregabalin $600 \mathrm{mg} /$ day

B.

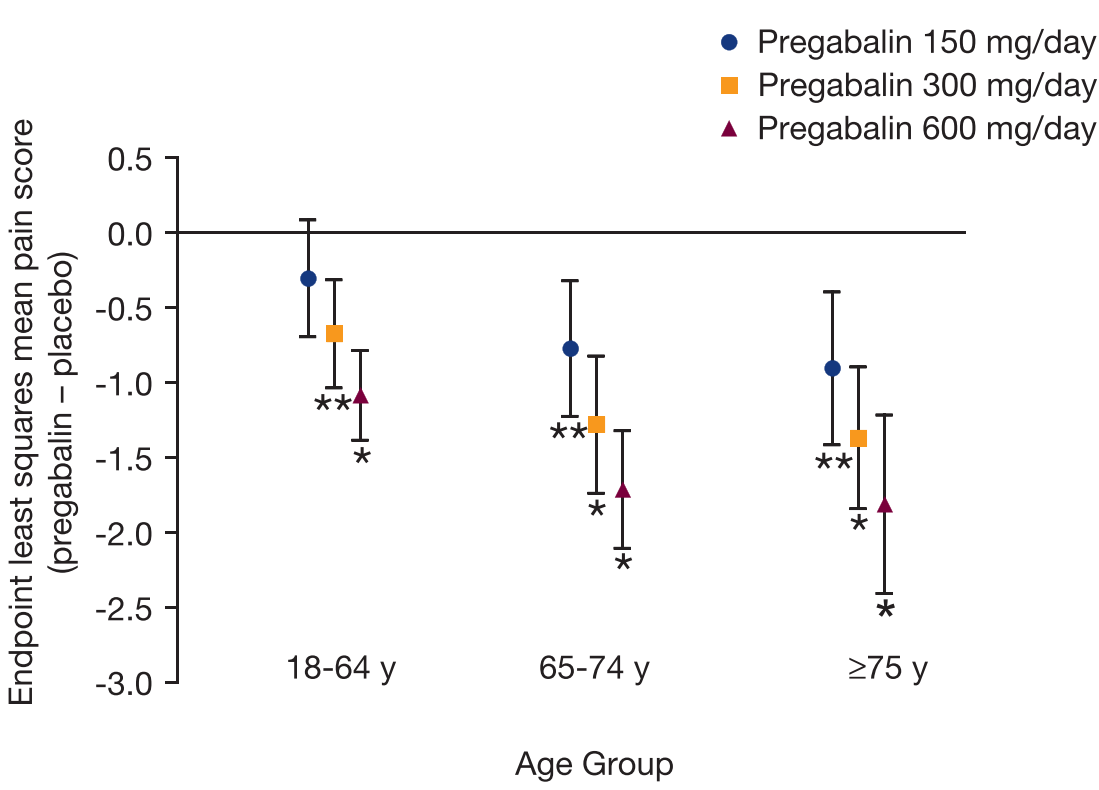

Figure 3 Placebo-adjusted endpoint mean pain by pregabalin dosage. The upper panel (A) shows placebo-adjusted endpoint mean pain for pooled age groups. The lower panel (B) shows placebo-adjusted endpoint mean pain by age and dosage group. Bars represent the $95 \%$ confidence interval. ${ }^{*} p<0.0001$ versus placebo. ${ }^{*} p \leq 0.0009$ versus placebo.

within the range of those observed in a systematic review of pregabalin in patients with $\mathrm{PHN}$ and DPN [26]. In this very difficult to treat patient population, up to $49 \%$ of patients finished treatment with pregabalin at a low pain state of pain scores $\leq 3$, which is commonly associated with significantly less functional impairment and improved activities of daily living compared with moderate and severe pain states [27]. The relative risks for the most common AEs with pregabalin did not appear to be compromised by increasing age or type of neuropathic pain; however, a trend between AE-related discontinuations and age in patients was observed, particularly in patients with PHN. A study of patients in general practice in the United Kingdom found that nearly half of all patients newly prescribed pregabalin for neuropathic pain were aged $\geq 65$ years [28]. This 
Table 2 Clinically important pain outcomes by age and dose group

\begin{tabular}{|c|c|c|c|c|c|}
\hline & \multicolumn{2}{|c|}{$\geq 30 \%$ Pain relief, n (\%) } & \multicolumn{2}{|c|}{$\geq 50 \%$ Pain relief, $n$ (\%) } & \multirow[t]{2}{*}{ Endpoint pain score $\leq 3, \mathrm{n}(\%)^{*}$} \\
\hline & BOCF & LOCF & BOCF & LOCF & \\
\hline \multicolumn{6}{|l|}{ 18-64 years } \\
\hline Placebo & $153(35.7)$ & $163(38.1)$ & $94(22.0)$ & $98(22.9)$ & $111(25.9)$ \\
\hline Pregabalin $150 \mathrm{mg} / \mathrm{d}$ & $72(39.3)$ & $74(40.4)$ & $45(24.6)$ & $46(25.1)$ & $50(27.3)$ \\
\hline Pregabalin $300 \mathrm{mg} / \mathrm{d}$ & $109(48.0)$ & $120(52.9)$ & $73(32.2)$ & $82(36.1)$ & $92(40.5)$ \\
\hline Pregabalin $600 \mathrm{mg} / \mathrm{d}$ & 199 (51.3) & $236(60.8)$ & $153(39.4)$ & $179(46.1)$ & $170(43.8)$ \\
\hline \multicolumn{6}{|l|}{$65-74$ years } \\
\hline Placebo & $73(24.6)$ & $80(26.9)$ & $47(15.8)$ & $51(17.2)$ & $57(19.2)$ \\
\hline Pregabalin $150 \mathrm{mg} / \mathrm{d}$ & $45(34.6)$ & $48(36.9)$ & $31(23.8)$ & $32(24.6)$ & $34(26.2)$ \\
\hline Pregabalin $300 \mathrm{mg} / \mathrm{d}$ & $56(44.8)$ & $68(54.4)$ & $38(30.4)$ & $46(36.8)$ & $43(34.4)$ \\
\hline Pregabalin $600 \mathrm{mg} / \mathrm{d}$ & $109(54.0)$ & $132(65.3)$ & $83(41.1)$ & $99(49.0)$ & $91(45.0)$ \\
\hline \multicolumn{6}{|l|}{$\geq 75$ years } \\
\hline Placebo & $39(21.0)$ & $42(22.6)$ & $22(11.8)$ & $23(12.4)$ & $24(12.9)$ \\
\hline Pregabalin $150 \mathrm{mg} / \mathrm{d}$ & $40(35.7)$ & $46(41.1)$ & $28(25.0)$ & $32(28.6)$ & $36(32.1)$ \\
\hline Pregabalin $300 \mathrm{mg} / \mathrm{d}$ & $43(30.1)$ & $64(44.8)$ & $30(21.0)$ & $42(29.4)$ & $38(26.6)$ \\
\hline Pregabalin $600 \mathrm{mg} / \mathrm{d}$ & $24(33.8)$ & $41(57.7)$ & $18(25.4)$ & $32(45.1)$ & $35(49.3)$ \\
\hline
\end{tabular}

LOCF, last observation carried forward; BOCF, baseline observation carried forward.

*Pain score $\leq 3$ at endpoint on the Daily Pain Rating Scale $(0=$ no pain to $10=$ worst possible pain) based on LOCF analysis.

underscores the importance of better understanding the efficacy and safety of pregabalin in older patients.

In all but one of the studies in this analysis, patients were assigned a dose of pregabalin (or placebo) based on the randomization schema of the study and not titrated based on response to pregabalin. Renal excretion is compromised in up to one-half of older patients [4], which potentially affects plasma levels of pregabalin. In some, but not all, studies in this pooled analysis, the assigned dosage of pregabalin (e.g. $600 \mathrm{mg} /$ day) was reduced (e.g. $300 \mathrm{mg} /$ day) based on the patient's renal function $\left(\mathrm{Cl}_{\mathrm{cr}}\right)$ at baseline. Because of these age-related impairments and varying criteria for dose reductions based on $\mathrm{CL}_{\mathrm{cr}}$ measurements, it cannot be assumed that patients in a particular dosage group had identical exposure to pregabalin, and this may have influenced the incidence of AEs in the higher dosage groups. Given that all 3 dosages of pregabalin were shown to significantly reduce pain in older patients with neuropathic pain, it is feasible to assume that some of the patients assigned to the higher dosage group may have achieved adequate pain relief with a lower dosage of pregabalin. Dizziness and somnolence are the most common AEs among older patients and potentially can be minimized by initiating pregabalin at low doses and slowly titrating to a dose at which the patient experiences pain relief, while taking into account any impairment in renal function. Titration of pregabalin to the lowest effective dose may be especially important for older patients with PHN.

The high placebo response in patients aged 18 to 64 years in the current pooled analysis may partially explain the lack of significant reduction in endpoint mean pain score for the pregabalin $150-\mathrm{mg} /$ day dosage in this group. Interestingly, in the current analysis, a significant difference was found in placebo response on pain between younger (age $<65$ years) and older patients (age $\geq 65$ years). A similar phenomenon has been observed in a pooled analysis of rizatriptan in patients with migraine [29]. It is unclear why the placebo response on mean pain scores differed between younger and older patients. Placebo response in clinical studies of pain may be driven by an expectation for benefit mediated via endogenous opioid and cholecystokinin pathway activation [30]. This might suggest that there is an effect of age on these systems. Perhaps younger patients with neuropathic pain enrolled in clinical studies have higher expectations for a benefit than older patients.

The choice of analgesic in patients with neuropathic pain of any age depends on the type of neuropathic pain, potential for AEs, comorbid conditions, and risk for drug-drug interactions. Comparison of the guidelines from the International Association for the Study of Pain Neuropathic Pain Special Interest Group, European Federation for Neurological Societies, and Canadian Pain Society found a consensus for the use of TCAs, gabapentin, and pregabalin as first-line treatments for neuropathic pain [31]. Older patients tend to take several medications and have concurrent medical conditions. The American Geriatric Society (AGS) recommends against the use of tertiary TCAs (e.g. amitriptyline) for the treatment of pain in older patients (age $\geq 75$ years) because of safety risks including cardiovascular effects, orthostatic hypotension, and cognitive impairment [32]. 
Table 3 Most common adverse events by treatment group, age, and type of neuropathic pain

\begin{tabular}{|c|c|c|c|c|c|c|c|c|}
\hline \multirow[b]{2}{*}{ Adverse event } & \multicolumn{2}{|c|}{ Placebo, n (\%) } & \multicolumn{2}{|c|}{$\begin{array}{l}\text { Pregabalin } 150 \\
\mathrm{mg} \text { day, n (\%) }\end{array}$} & \multicolumn{2}{|c|}{$\begin{array}{l}\text { Pregabalin } 300 \\
\text { mg/day, n (\%) }\end{array}$} & \multicolumn{2}{|c|}{ 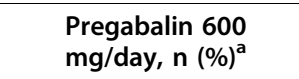 } \\
\hline & $\begin{array}{c}\text { DPN } \\
(n=558)\end{array}$ & $\begin{array}{c}\text { PHN } \\
(n=363)\end{array}$ & $\begin{array}{c}\text { DPN } \\
(n=176)\end{array}$ & $\begin{array}{c}\text { PHN } \\
(n=251)\end{array}$ & $\begin{array}{c}\text { DPN } \\
(n=266)\end{array}$ & $\begin{array}{c}\text { PHN } \\
(n=230)\end{array}$ & $\begin{array}{c}\text { DPN } \\
(n=513)\end{array}$ & $\begin{array}{c}\text { PHN } \\
(n=159)\end{array}$ \\
\hline \multicolumn{9}{|l|}{ Dizziness } \\
\hline Age $18-64$ y & $16(4.4)$ & $9(13.2)$ & $7(5.5)$ & $4(7.0)$ & $40(22.0)$ & $11(24.0)$ & $85(24.7)$ & $23(48.9)$ \\
\hline Age $65-74$ y & $8(5.1)$ & $10(7.0)$ & $3(7.7)$ & $13(14.1)$ & $16(25.8)$ & $25(39.1)$ & $46(33.1)$ & $25(36.2)$ \\
\hline Age $\geq 75$ y & $2(5.9)$ & $17(11.2)$ & $2(20.0)$ & 22 (21.6) & $6(27.3)$ & 37 (30.6) & $11(36.7)$ & $13(30.2)$ \\
\hline \multicolumn{9}{|l|}{ Somnolence } \\
\hline Age $18-64$ y & $14(3.8)$ & $5(7.4)$ & $5(3.9)$ & $7(12.3)$ & $24(13.2)$ & $3(6.7)$ & $45(13.1)$ & $13(27.7)$ \\
\hline Age $65-74$ y & $2(1.3)$ & $5(3.5)$ & $2(5.1)$ & $9(9.8)$ & $11(17.7)$ & $14(21.9)$ & $16(11.5)$ & $20(29.0)$ \\
\hline Age $\geq 75 y$ & 0 & $10(6.6)$ & $2(20.0)$ & $12(11.8)$ & $3(13.6)$ & $25(20.7)$ & 7 (23.3) & $11(25.6)$ \\
\hline \multicolumn{9}{|l|}{ Peripheral edema } \\
\hline Age 18-64 y & $27(7.4)$ & $2(2.9)$ & $6(4.7)$ & $3(5.3)$ & $15(8.2)$ & $3(6.7)$ & $53(15.4)$ & $6(12.8)$ \\
\hline Age 65-74 y & $10(6.3)$ & $6(4.2)$ & $3(7.7)$ & $9(9.8)$ & $9(14.5)$ & $8(12.5)$ & $24(17.3)$ & $12(17.4)$ \\
\hline Age $\geq 75$ y & $3(8.8)$ & $6(3.9)$ & $1(10.0)$ & $7(6.9)$ & $2(9.1)$ & $24(19.8)$ & $5(16.7)$ & $4(9.3)$ \\
\hline \multicolumn{9}{|l|}{ Asthenia } \\
\hline Age $18-64$ y & $11(3.0)$ & $4(5.9)$ & $3(2.4)$ & $2(3.5)$ & $8(4.4)$ & $3(6.7)$ & $24(7.0)$ & $3(6.4)$ \\
\hline Age $65-74$ y & 0 & $6(4.2)$ & 0 & $6(6.5)$ & $4(6.5)$ & 0 & $14(10.1)$ & $7(10.1)$ \\
\hline Age $\geq 75$ y & $1(2.9)$ & $7(4.6)$ & $1(10.0)$ & $5(4.9)$ & $1(4.5)$ & $4(3.3)$ & $6(20.0)$ & $2(4.7)$ \\
\hline \multicolumn{9}{|l|}{ Dry mouth } \\
\hline Age $18-64$ y & $6(1.6)$ & $2(2.9)$ & $1(0.8)$ & $5(8.8)$ & $6(3.3)$ & 0 & $18(5.2)$ & $8(17.0)$ \\
\hline Age $65-74$ y & $1(0.6)$ & $6(4.2)$ & 0 & $9(9.8)$ & $4(6.5)$ & $6(9.4)$ & $10(7.2)$ & $9(13.0)$ \\
\hline Age $\geq 75$ y & 0 & $5(3.3)$ & $2(20.0)$ & $5(4.9)$ & $3(13.6)$ & $8(6.6)$ & $2(6.7)$ & $6(14.0)$ \\
\hline \multicolumn{9}{|l|}{ Weight gain } \\
\hline Age 18-64 y & $3(0.8)$ & $1(1.5)$ & $6(4.7)$ & $3(5.3)$ & $9(4.9)$ & $4(8.9)$ & $34(9.9)$ & $5(10.6)$ \\
\hline Age $65-74$ y & $1(0.6)$ & $2(1.4)$ & $1(2.6)$ & $1(1.1)$ & $1(1.6)$ & $2(3.1)$ & $10(7.2)$ & $9(13.0)$ \\
\hline Age $\geq 75$ y & $1(2.9)$ & 0 & $1(10.0)$ & $1(1.0)$ & 0 & $8(6.6)$ & $1(3.3)$ & $5(11.6)$ \\
\hline \multicolumn{9}{|l|}{ Infection } \\
\hline Age 18-64 y & $25(6.8)$ & $2(2.9)$ & $10(7.9)$ & $9(15.8)$ & $17(9.3)$ & $4(8.9)$ & $10(2.9)$ & $1(2.1)$ \\
\hline Age $65-74$ y & $8(5.1)$ & $7(4.9)$ & $4(10.3)$ & $7(7.6)$ & $5(8.1)$ & $3(4.7)$ & $6(4.3)$ & $1(1.4)$ \\
\hline Age $\geq 75$ y & $2(5.9)$ & $3(2.0)$ & 0 & $6(5.9)$ & $1(4.5)$ & $11(9.1)$ & $1(3.3)$ & $2(4.7)$ \\
\hline
\end{tabular}

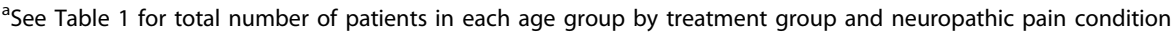
DPN: diabetic peripheral neuropathy; PHN: postherpetic neuralgia

Despite these AGS recommendations, several claimsbased studies have found high rates of potentially inappropriate use of TCAs, in particular amitriptyline, in older patients with neuropathic pain conditions $[5,33]$. Analgesics metabolized by cytochrome P450 (e.g. duloxetine) should be used with caution in patients who take multiple medications because of the potential for drugdrug interactions with drugs that inhibit or are metabolized by cytochrome P450 [34]. Pregabalin is not metabolized by cytochrome P450 and has no known drugdrug interactions [8]; however, appropriate dose reductions should be made in older patients with renal impairment [34].

Whether the results from controlled clinical trials, which have strict patient enrollment criteria, are generalizable to patients encountered in clinical practice is always a concern. Pregabalin significantly reduced pain and sleep interference scores compared with pretreatment levels across a broad range of patients with refractory neuropathic pain in an open-label routine care setting [35]. Several realworld, retrospective, claims-based studies have confirmed the results of randomized controlled clinical studies showing a benefit for pregabalin in various neuropathic pain conditions. In patients with PHN, opioid use significantly decreased following initiation of pregabalin, whereas it increased following initiation of gabapentin [36]. In older patients (age $\geq 65$ years) with fibromyalgia, many of whom had comorbid neuropathic pain conditions, initiation of pregabalin was associated with significantly fewer physician office visits and total outpatient visits compared with pretreatment levels [37]. Finally, in a general practice setting in the United Kingdom, use of pregabalin was associated with decreased use of other analgesics in patients with neuropathic pain conditions [28].

Limitations of this analysis include that it was a post hoc analysis. Unlike randomized clinical trials, the age 


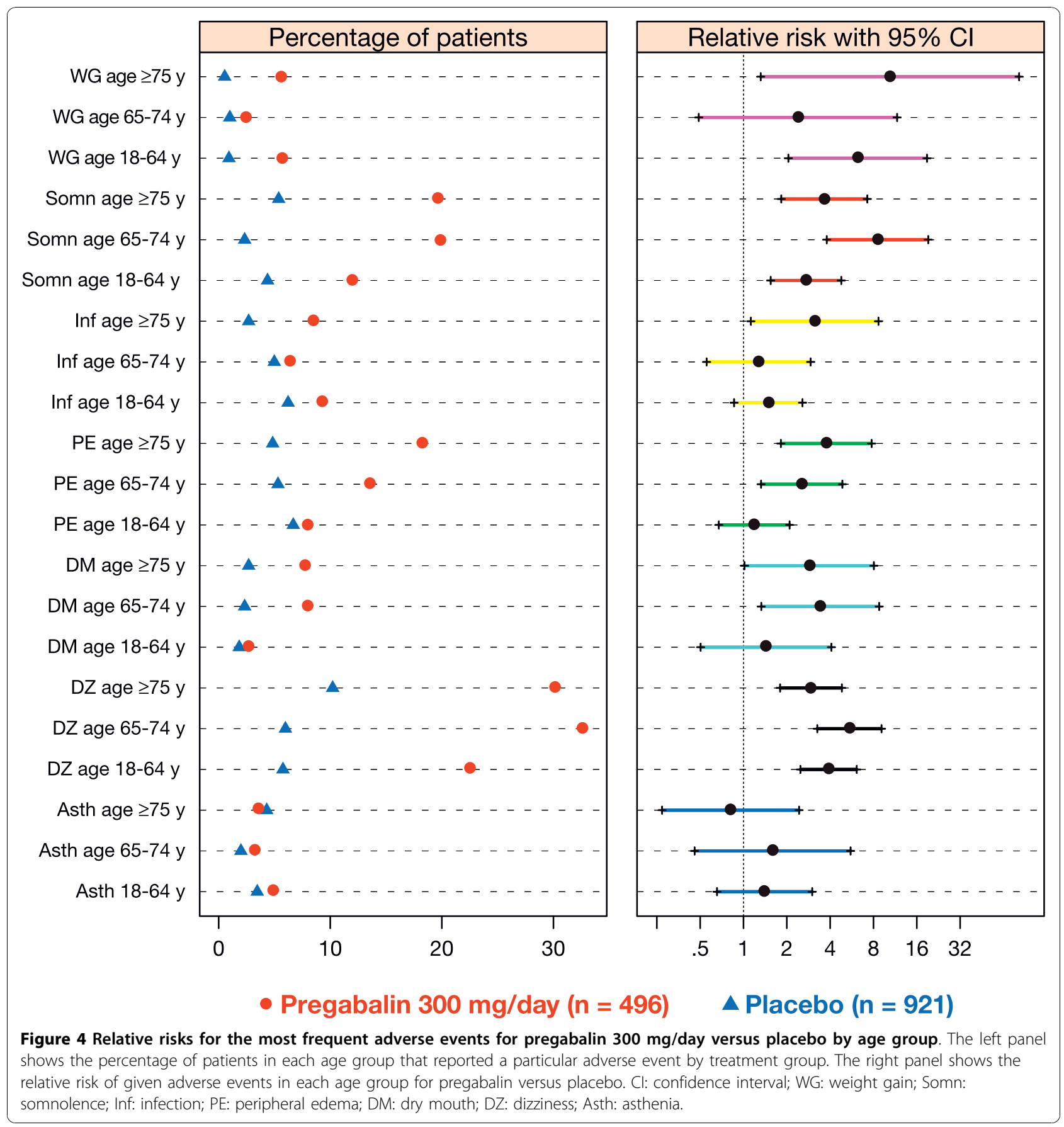

and dosage groups were not balanced for the number of patients resulting in fewer patients evaluated in the older groups, especially at the highest pregabalin dosage. Analysis of data across multiple clinical trials with slightly different eligibility criteria and 2 different neuropathic pain conditions may have contributed to some of the variability in the results. Furthermore, large placebo responses in clinical trials of neuropathic pain may confound assessment of treatment differences. Because the study populations in this analysis were selected based on inclusion and exclusion criteria to express particular characteristics, the results may not be immediately generalizable to the patient population encountered in clinical practice.

\section{Conclusions}

In this post hoc pooled analysis, pregabalin 150 to 600 $\mathrm{mg} /$ day reduced pain and improved sleep interference in 
Table 4 Discontinuations owing to adverse events by age, treatment group, and neuropathic pain condition

\begin{tabular}{lcccc}
\hline & $\begin{array}{c}\text { Placebo, } \\
\mathbf{n}(\%)^{\mathbf{a}}\end{array}$ & $\begin{array}{c}\text { Pregabalin } \\
\mathbf{1 5 0} \\
\mathbf{m g / d a y , ~} \mathbf{n} \\
\mathbf{( \% )}^{\mathbf{a}}\end{array}$ & $\begin{array}{c}\text { Pregabalin } \\
\mathbf{3 0 0} \\
\mathbf{m g / d a y , ~} \mathbf{n} \\
\mathbf{( \% )}^{\mathbf{a}}\end{array}$ & $\begin{array}{c}\text { Pregabalin } \\
\mathbf{6 0 0} \\
\mathbf{m g} / \mathbf{d a y}, \mathbf{n} \\
\mathbf{( \% )}^{\mathbf{a}}\end{array}$ \\
\hline DPN & & & & \\
Age 18-64 y & $14(3.8)$ & $3(2.4)$ & $14(7.7)$ & $42(12.2)$ \\
Age 65-74 y & $12(7.6)$ & $3(7.7)$ & $9(14.5)$ & $26(18.7)$ \\
Age $\geq 75 y$ & $3(8.8)$ & $1(10.0)$ & $3(13.6)$ & $7(23.3)$ \\
\hline PHN & & & & \\
Age 18-64 y & $4(5.9)$ & $5(8.8)$ & $3(6.7)$ & $12(25.5)$ \\
Age 65-74 y & $11(7.7)$ & $5(5.4)$ & $8(12.5)$ & $15(21.7)$ \\
Age $\geq 75 y$ & $9(5.9)$ & $11(10.8)$ & $32(26.4)$ & $13(30.2)$ \\
\hline
\end{tabular}

${ }^{\mathrm{a}} \mathrm{See}$ Table 1 for total number of patients in each age group by treatment group and neuropathic pain condition

DPN: diabetic peripheral neuropathy; PHN: postherpetic neuralgia

older patients (age $\geq 65$ years) with neuropathic pain. The improvements in pain in older patients were comparable to those observed in younger patients and clinically meaningful improvements in pain were observed in all age groups. The most common AEs were somnolence, weight gain, dry mouth, asthenia, dizziness, peripheral edema, and infection. The incidence of AEs did not appear to be related to older age or type of neuropathic pain, but did appear to be related to pregabalin dose. Slow titration of pregabalin to the lowest effective dose that provides pain relief should minimize the risk of AEs in older patients with neuropathic pain.

\section{List of Abbreviations Used}

AEs: adverse events; AGS: American Geriatrics Society; CI: confidence interval; $\mathrm{CL}_{\mathrm{cr}}$ : creatinine clearance; DPN: diabetic peripheral neuropathy; DPRS: Daily Pain Rating Scale; DSIS: Daily Sleep Interference Scale; PHN: postherpetic neuralgia; TCAs: tricyclic antidepressants

\section{Additional material}

Additional file 1: Relative risks for the most frequent adverse events for pregabalin $150 \mathrm{mg} /$ day versus placebo by age group. The left panel shows the percentage of patients in each age group that reported a particular adverse event by treatment group. The right panel shows the relative risk of given adverse events in each age group for pregabalin versus placebo.

Additional file 2: Relative risks for the most frequent adverse events for pregabalin $600 \mathrm{mg} /$ day versus placebo by age group The left panel shows the percentage of patients in each age group that reported a particular adverse event by treatment group. The right panel shows the relative risk of given adverse events in each age group for pregabalin versus placebo.

\section{Acknowledgements}

This post hoc analysis and all of the original studies were funded by Pfizer Inc. In addition to funding, Pfizer provided scientific and technical expertise in study design, data collection, and data analysis. The authors are full-time employees of Pfizer Inc. All authors were involved in the development of the manuscript and had final control of publication. Editorial support was provided by Alison Gagnon of UBC Scientific Solutions and funded by Pfizer Inc.

\section{Authors' contributions}

DS and GZ conceived the post hoc analysis and DS, GZ, TKM, RC, and BE participated in data analysis and interpretation. BE performed the statistical analyses. All authors participated in manuscript preparation and read and approved the final manuscript.

\section{Competing interests}

David Semel, T. Kevin Murphy, Gergana Zlateva, Raymond Cheung, and Birol Emir are full-time employees of Pfizer Inc.

Received: 1 April 2010 Accepted: 5 November 2010

Published: 5 November 2010

\section{References}

1. Haslam C, Nurmikko T: Pharmacological treatment of neuropathic pain in older persons. Clin Interv Aging 2008, 3:111-120.

2. Salazar JA, Poon I, Nair M: Clinical consequences of polypharmacy in elderly: expect the unexpected, think the unthinkable. Expert Opin Drug Saf 2007, 6:695-704.

3. Delafuente JC: Understanding and preventing drug interactions in elderly patients. Crit Rev Oncol Hematol 2003, 48:133-143.

4. Klotz U: Pharmacokinetics and drug metabolism in the elderly. Drug Metab Rev 2009, 41:67-76.

5. Oster G, Berger A, Dukes E, Edelsberg J, McCarberg B: Use of potentially inappropriate pain-related medications in older adults with painful neuropathic disorders. Am J Geriatr Pharmacother 2004, 2:163-170.

6. Lachaine J, Gordon A, Choinière M, Collet JP, Dion D, Tarride JE: Painful neuropathic disorders: an analysis of the Régie de I'Assurance Maladie du Québec database. Pain Res Manag 2007, 12:31-37.

7. Attal N, Cruccu G, Haanpaa M, Hansson P, Jensen TS, Nurmikko T, Sampaio C, Sindrup S, Wiffen P, EFNS Task Force: EFNS guidelines on pharmacological treatment of neuropathic pain. Eur J Neurol 2006, 13:1153-1169.

8. Stacey BR, Swift JN: Pregabalin for neuropathic pain based on recent clinical trials. Curr Pain Headache Rep 2006, 10:179-184

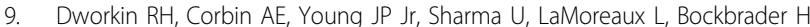
Garofalo EA, Poole RM: Pregabalin for the treatment of postherpetic neuralgia: a randomized, placebo-controlled trial. Neurology 2003 60:1274-1283.

10. Lesser $H$, Sharma U, LaMoreaux L, Poole RM: Pregabalin relieves symptoms of painful diabetic neuropathy: a randomized controlled trial. Neurology 2004, 63:2104-2110.

11. Richter RW, Portenoy R, Sharma U, LaMoreaux L, Bockbrader H, Knapp LE: Relief of painful diabetic peripheral neuropathy with pregabalin: $a$ randomized, placebo-controlled trial. J Pain 2005, 6:253-260.

12. Rosenstock J, Tuchman M, LaMoreaux L, Sharma U: Pregabalin for the treatment of painful diabetic peripheral neuropathy: a double-blind, placebo-controlled trial. Pain 2004, 110:628-638.

13. Sabatowski $R$, Galvez $R$, Cherry DA, Jacquot $F$, Vincent $E$, Maisonobe $P$, Versavel M, 1008-045 Study Group: Pregabalin reduces pain and improves sleep and mood disturbances in patients with post-herpetic neuralgia: results of a randomised, placebo-controlled clinical trial. Pain 2004, 109:26-35.

14. Freynhagen R, Strojek K, Griesing T, Whalen E, Balkenohl M: Efficacy of pregabalin in neuropathic pain evaluated in a 12-week, randomised, double-blind, multicentre, placebo-controlled trial of flexible-and fixeddose regimens. Pain 2005, 115:254-263.

15. van Seventer R, Feister HA, Young JP Jr, Stoker M, Versavel M, Rigaudy L: Efficacy and tolerability of twice-daily pregabalin for treating pain and related sleep interference in postherpetic neuralgia: a 13-week, randomized trial. Curr Med Res Opin 2006, 22:375-384.

16. Tölle T, Freynhagen R, Versavel M, Trostmann U, Young JP Jr: Pregabalin for relief of neuropathic pain associated with diabetic neuropathy: a randomized, double-blind study. Eur J Pain 2008, 12:203-213. 
17. Arezzo JC, Rosenstock J, LaMoreaux L, Pauer L: Efficacy and safety of pregabalin $600 \mathrm{mg} / \mathrm{d}$ for treating painful diabetic peripheral neuropathy: a double-blind placebo-controlled trial. BMC Neurol 2008, 8:33.

18. Berlin JA, Santanna J, Schmid CH, Szczech LA, Feldman HI: Individual patient-versus group-level data meta-regressions for the investigation of treatment effect modifiers: ecological bias rears its ugly head. Stat Med 2002, 21:371-387.

19. Higgins JP, Thompson SG: Controlling the risk of spurious findings from meta-regression. Stat Med 2004, 23:1663-1682.

20. Lambert PC, Sutton AJ, Abrams KR, Jones DR: A comparison of summary patient-level covariates in meta-regression with individual patient data meta-analysis. J Clin Epidemiol 2002, 55:86-94.

21. Dworkin RH, Thakur R, Griesing T, Sharma U, Young JP: Randomized clinical trials of pregabalin for neuropathic pain: methods, results, and implications. Prog Neurother Neuropsychopharmacol 2008, 3:167-187.

22. European Medicines Agency Scientific Discussion-Lyrica. [http://www. ema.europa.eu/docs/en_GB/document_library/EPAR_-_Scientific_Discussion/ human/000546/WC500046600.pdf].

23. A placebo-controlled trial of pregabalin and amitriptyline for treatment of painful diabetic peripheral neuropathy. [http://www.clinicalstudyresults. org/documents/company-study_1952_0.pdf].

24. Dworkin RH, Turk DC, Wyrwich KW, Beaton D, Cleeland CS, Farrar JT, Haythornthwaite JA, Jensen MP, Kerns RD, Ader DN, et al: Interpreting the clinical importance of treatment outcomes in chronic pain clinical trials: IMMPACT recommendations. J Pain 2008, 9:105-121.

25. Moore RA, Eccleston C, Derry S, Wiffen P, Bell RF, Straube S, McQuay H: "Evidence" in chronic pain-establishing best practice in the reporting of systematic reviews. Pain 2010.

26. Moore RA, Straube S, Wiffen PJ, Derry S, McQuay HJ: Pregabalin for acute and chronic pain in adults. Cochrane Database Syst Rev 2009, CD007076.

27. McDermott AM, Toelle TR, Rowbotham DJ, Schaefer CP, Dukes EM: The burden of neuropathic pain: results from a cross-sectional survey. Eur J Pain 2006, 10:127-135.

28. Berger A, Sadosky A, Dukes E, Edelsberg J, Oster G: Use of pregabalin in patients with painful neuropathic disorders under the care of general practitioners in the U.K. Pain Pract 2009, 9:18-34.

29. Ho TW, Fan X, Rodgers A, Lines CR, Winner P, Shapiro RE: Age effects on placebo response rates in clinical trials of acute agents for migraine: pooled analysis of rizatriptan trials in adults. Cephalalgia 2009, 29:711-718.

30. Benedetti F: Mechanisms of placebo and placebo-related effects across diseases and treatments. Annu Rev Pharmacol Toxicol 2008, 48:33-60.

31. O'Connor AB, Dworkin RH: Treatment of neuropathic pain: an overview of recent guidelines. Am J Med 2009, 122:(10 Suppl):S22-S32.

32. American Geriatrics Society Panel on the Pharmacological Management of Persistent Pain in Older Persons: Pharmacological management of persistent pain in older persons. Pain Med 2009, 10:1062-1083.

33. Berger A, Dukes E, Edelsberg J, Stacey B, Oster G: Use of tricyclic antidepressants in older patients with diabetic peripheral neuropathy. Clin J Pain 2007, 23:251-258.

34. McGeeney BE: Pharmacological management of neuropathic pain in older adults: an update on peripherally and centrally acting agents. $J$ Pain Symptom Manage 2009, 38(2 Suppl):S15-S27.

35. Freynhagen $R$, Grond $S$, Schüpfer $G$, Hagebeuker A, Schmelz M, Ziegler D, Von Giesen HJ, Junker U, Wagner KJ, Konrad C: Efficacy and safety of pregabalin in treatment refractory patients with various neuropathic pain entities in clinical routine. Int J Clin Pract 2007, 61:1989-1996.

36. Gore M, Sadosky A, Tai KS, Stacey B: A retrospective evaluation of the use of gabapentin and pregabalin in patients with postherpetic neuralgia in usual-care settings. Clin Ther 2007, 29:1655-1670.

37. Gore M, Sadosky A, Zlateva G, Clauw D: Initial use of pregabalin, patterns of pain-related pharmacotherapy, and healthcare resource use among older patients with fibromyalgia. Am J Manag Care 2010, 16:S144-153.

\section{Pre-publication history}

The pre-publication history for this paper can be accessed here: http://www.biomedcentral.com/1471-2296/11/85/prepub

doi:10.1186/1471-2296-11-85

Cite this article as: Semel et al: Evaluation of the safety and efficacy of pregabalin in older patients with neuropathic pain: results from a pooled analysis of 11 clinical studies. BMC Family Practice 2010 11:85.

\section{Submit your next manuscript to BioMed Central and take full advantage of:}

- Convenient online submission

- Thorough peer review

- No space constraints or color figure charges

- Immediate publication on acceptance

- Inclusion in PubMed, CAS, Scopus and Google Scholar

- Research which is freely available for redistribution 